\title{
Two outbreaks of botulism associated with consumption of green olive paste, France, September 2011
}

J M Pingeon ${ }^{1}$, C Vanbockstael ${ }^{2}$, M R Popoff 3 , L A King ${ }^{4}$, B Deschamps ${ }^{5}$, G Pradel ${ }^{6}$, H Dupont $^{7}$, A Spanjaard ${ }^{6}$, A Houdard $^{8}$, C Mazuet $^{3}$, B Belaizi ${ }^{9}$, S Bourgeois 6 , S Lemgueres ${ }^{6}$, K Debbat $^{6}$, P Courant $^{6}$, R Quirin ${ }^{5}$, P Malfait (Philippe.MALFAIT@ars.sante.fr) ${ }^{10}$

1. Regional Health Agency of Provence-Alpes-Côte d’Azur, Avignon, France

2. Regional office of the French Institute for Public Health Surveillance (Institut de Veille Sanitaire, InVS), Lille, France

3. National Reference Centre for Anaerobic Bacteria and Botulism, Pasteur Institute, Paris, France

4. French Institute for Public Health Surveillance (Institut de Veille Sanitaire, InVS), Saint Maurice, France

5. District Veterinary Services, Avignon, France

6. Avignon Hospital, Avignon, France

7. Amiens Hospital, Amiens, France

8. Regional Health Agency of Picardy, Amiens, France

9. District Veterinary Services, Amiens, France

10. Regional office of the French Institute for Public Health Surveillance (Institut de Veille Sanitaire, InVS), Marseille, France

Citation style for this article:

Pingeon JM, Vanbockstael C, Popoff MR, King LA, Deschamps B, Pradel G, Dupont H, Spanjaard A, Houdard A, Mazuet C, Belaizi B, Bourgeois S, Lemgueres S, Debbat K, Courant P, Quirin R, Malfait P. Two outbreaks of botulism associated with consumption of green olive paste, France, September 2011.

Euro Surveill. 2011;16(49):pii=20035. Available online: http://www.eurosurveillance.org/ViewArticle.aspx?Articleld=20035

Article published on 8 December 2011

Two family outbreaks of botulism (a total of nine cases) were identified in south-east and northern France in early September 2011. The source of infection was considered to be a ground green olive paste. Botulinum type $A$ toxin was identified in seven cases and in the incriminated olive paste. Incorrect sterilisation techniques were observed at the artisanal producer's workshop. These episodes highlight the potential public health threat of Clostridium botulinum linked to inadequate sterilisation of food products.

\section{Outbreak description}

In early September 2011, local health authorities were notified by a hospital clinician of an outbreak of five suspected cases of botulism (Outbreak 1) among eight persons who attended a family dinner in the Vaucluse department in the south-east of France. The five, aged in their mid-50s to mid-80s, presented with classic symptoms of botulism (gastrointestinal symptoms followed by descending paralysis) 24 to 36 hours after the meal and were hospitalised the same or the following day after symptom onset. All five rapidly developed quadriplegia and required intubation and mechanical ventilation. A trivalent antitoxin was administered to all five. As of the end of November (latest information available), all five were still hospitalised.

A further suspected case, who had attended the same family dinner, was initially asymptomatic, but went on to develop mild symptoms of botulism (double vision, ptosis and difficulty in swallowing), seven days after the family meal. This person was hospitalised the day of symptom onset. The patient did not develop paralysis of the limbs or respiratory muscles and was discharged from hospital three days after admission.
A second outbreak of three suspected cases (Outbreak 2) was reported two days following notification of Outbreak 1, among six persons who attended another family dinner, in the Somme department in the north of France. The three suspected cases, all aged in their 20s, presented with classic symptoms of botulism one day after the dinner and were hospitalised that day. All three rapidly developed quadriplegia and required intubation and mechanical ventilation. A trivalent antitoxin was administered to all three. The duration of hospitalisation ranged from 34 to 58 days. Two asymptomatic persons who also attended the dinner were hospitalised for observation and were discharged after 48 hours.

\section{Oubreak investigation}

An investigation was undertaken the day Outbreak 1 was notified, to confirm the diagnosis, identify any additional cases and the vehicle of intoxication and to put in place appropriate control measures.

When the first outbreak was notified, the French Ministry of Health issued an urgent message about the outbreaks to all French hospitals and poison control centres. Hospital clinicians were reminded to report immediately all clinical suspicions of botulism to the local health authorities, using the mandatory notification system.

The local health authorities documented the food consumption of the suspected cases in the two to three days before symptom onset and particularly during the meal shared by each family in the two outbreaks, including type of food, brand and date and place of purchase. 


\section{Clinical samples}

Serum, gastric juice and stool samples from the suspected cases and samples recovered from leftover foods from the two family meals were analysed by the National Reference Centre for Anaerobic Bacteria and Botulism at the Pasteur Institute in Paris. The presence of botulinum toxin type A was confirmed by the mouse lethality test and by seroprotection with specific antibodies [1]. The presence of Clostridium botulinum was investigated by real-time PCR amplification of the type $A, B$ and $E$ neurotoxin genes, and strain isolation and characterisation [1].

Type A botulinum toxin was identified in serum samples by the mouse lethality test from seven of the nine suspected cases and C. botulinum was isolated from stool and/or gastric juice from the same seven cases. As the other two persons had clinical symptoms compatible with botulism and an epidemiological link with a laboratory-confirmed case, they were also considered as cases.

Serum samples taken from three asymptomatic people who had participated in the family meals - one in Oubreak 1 and two in Oubreak 2 - were negative for botulinum toxin.

\section{Food investigation}

In Outbreak 1, the eight family members had shared a single common meal at the start of September (24 to 36 hours before symptom onset in the first five cases), during which all five consumed ground green olive paste (containing green olives, garlic, capers and olive oil). The two asymptomatic participants did not report having consumed the paste. The case who presented later with a milder form of the disease, reported not to have consumed the paste, but to have used the knife that had been used to serve it. A dried-tomato paste was also eaten by some (number unknown) of the family members who attended the meal.

In Outbreak 2, consumption of ground green olive paste and a dried-tomato paste during the single common meal in early September (one day before symptom onset) was reported for all three cases. The asymptomatic participants did not report consumption of these products, with the exception of one participant who ate only the tomato paste.

Leftovers of the two meals were sent for testing two days after each meal had taken place. The national reference centre identified botulinum toxin type $A$ in the green olive paste from the meal in Outbreak 1, with toxin titres of 20,000 mouse lethal doses (MLD)/g. The dried-tomato paste, eaten by some of the family of Outbreak 1, was negative for botulinum toxin.

Type A botulinum toxin was also identified in the leftover olive paste (toxin titres of 2,000 $\mathrm{MLD} / \mathrm{g}$ ) and to a lesser extent in the tomato paste $(2 \mathrm{MLD} / \mathrm{g})$ from the meal in Outbreak 2.
C. botulinum type A was identified by real-time $P C R$ from all four food samples and isolated from three food samples (green olive paste leftovers from both meals and the leftover dried-tomato paste from the meal in Outbreak 2).

\section{Trace-back and environmental investigations}

The trace-back investigation found that the two families in Outbreaks 1 and 2 had eaten ground green olive paste that had been produced on 20 May 2011. The tomato paste eaten by members of Outbreak 1 had been produced on 26 July 2011, while that eaten by members of Outbreak 2 dated from 20 May 2011.

The green olive pastes and tomato pastes had been purchased by the families in two grocery stores in two neighbouring districts of the Provence region in south-east France, in late July and August 2011. They were sold in small glass jars with screw-top lids as part of a collection of several pastes, which are typical of this region. The products came from a local artisanal producer: they were produced in small quantities (the size of the batch of olive paste produced on 20 May was approximately 60 pots) and distributed principally to grocery stores under three different brand names, in a limited geographical area in the south-east of the country. The products were also sold in small quantities on the Internet.

An environmental investigation carried out by the district food control authority identified that the sterilisation process was incorrect, which affected not only the production of the two types of paste, but all goods made by this producer. No in-house quality assurance controls had been performed and the producer had not declared the food production to the local health authorities responsible for inspecting food producers.

\section{Public health measures}

The green olive paste was recalled nationally, via a local and national press release, the day after the first outbreak was notified. Following trace-back investigation, inspection of the production procedures and microbiological results suggesting that other products prepared using the same sterilisation process could also be at risk, all products of the producer involved were recalled two days after the press release was issued.

European countries were informed of the occurrence of the cases and the incriminated product via the Early Warning and Response System (EWRS) and the Epidemic Intelligence Information System (EPIS) of the European Centre for Disease Control, the International Food Safety Authorities Network (INFOSAN) of the World Health Organization and the Food and Agriculture Organization of the United Nations and via an alert in the European Union's Rapid Alert System for Food and Feed (RASFF), the day after the press release was issued and during the following two days. 
As of 6 December, no other case of botulism associated with this product has been identified in France or any other European Union Member State.

\section{Discussion}

Botulism is a rare disease in France and has been statutorily notifiable since 1986. Between 2007 and 2009, 47 cases were notified [2] and among the confirmed cases, botulinum type B toxin was identified in 33 and botulinum type A toxin in eight (three of the eight were infants). The last reported episode of botulism in France due to botulinum type A toxin was in Corsica in 2010 [3], in which five persons who attended the same meal developed severe botulism: one case died. This episode was linked to the consumption of home-preserved French beans in a salade niçoise.

Botulism due to type A toxin is characteristically associated with the consumption of vegetable products, especially home-canned vegetables, but some cases have been linked to commercially processed foods [4]. The probable food source in the outbreaks described here was a green olive paste produced by a local manufacturer using inadequate sterilisation techniques. Botulism food poisoning associated with incorrectly prepared olives has previously been documented $[5,6]$. Garlic, which was included in the preparation of the olive pastes involved in these outbreaks, has also been previously associated with botulism [7].

C. botulinum spores are present in the environment and can be present in foods that have not been subjected to a sufficiently high temperature during preparation $[8,9]$. If appropriate conditions exist within such foods, C. botulinum spores present can germinate, multiply and produce toxin. The environmental investigation carried out following the two outbreaks described in this report demonstrated that the sterilisation process used by the producer was incorrect. Our findings strongly suggest that the inadequate sterilisation process permitted spores of $C$. botulinum to survive the preparation process and consequently was the probable cause of the outbreaks.

These outbreaks highlight the potential public health threat of $C$. botulinum associated with inadequate sterilisation processes and underline the importance of monitoring practices of producers involved in smallscale food preparation.

References

1. Popoff M, Carlier JP, Poulain B. Botulisme. Maladies infectieuses [Botulism. Infectious diseases]. Paris: EMC (Elsevier Masson SAS); 2009. French.

2. Mazuet C, Bouvet C, King L, Popoff MR. Le botulisme humain en France, 2007-2009 [Human botulism in France, 2007-2009]. Bulletin épidemiologique, 2011;6:49-53. French. Available from: http://www.invs.sante.fr/beh/2011/06/beh_06_2011.pdf

3. Oriot C, D’Aranda E, Castanier M, Glaizal M, Galy C, Faivre A, et al. One collective case of type A foodborne botulism in Corsica. Clin Toxicol (Phila). 2011;49(8):752-4.

4. King LA; French Multidisciplinary Outbreak Investigation Team. Two severe cases or botulism associated with industrially produced chicken enchiladas, France, August 2008. Euro Surveill. 2008;13(37): $\mathrm{pii}=18978$. Available from: http://www. eurosurveillance.org/ViewArticle.aspx?Articleld =18978

5. Cawthorne A, Celentano LP, D’Ancona F, Bella A, Massari M, Annibali F, et al. Botulism and preserved green olives. Emerg Infect Dis. 11(5):781-2.

6. Fenicia L, Ferrini AM, Aureli P, Padovan MT. [Epidemic of botulism caused by black olives]. Industrie Alimentari. 1992;31:307-8. Italian.

7. Morse DL, Pickard LK, Guzewich JJ, Devine BD, Shayegani M. Garlic-in-oil associated botulism: episode leads to product modification. Am J Public Health 1990;80(11):1372-3.

8. Agence nationale de sécurité sanitaire de l'alimentation, environnement, travail (ANSES). Clostridium botulinum, Clostridium neurotoxigènes [Clostridium botulinum, neurotoxigenic Clostridium]. Paris: ANSES; 2010. French. [Accessed 8 Dec 2011]. Available from: http://www.anses.fr/ Documents/MIC-Fi-Clostridiumbotu.pdf

9. Centers for Disease Control and Prevention (CDC). Botulism associated with commercially canned chili sauce--Texas and Indiana, July 2007. MMWR Morb Mortal Wkly Rep. 2007;56(30):767-9. 